\title{
Sustainable Urban Transport Indicators: Case of Mega Cities of India"
}

\author{
S. Vijayalakshmi ${ }^{1 *}$ and Krishna Raj ${ }^{2}$ \\ 'Research Student, Institute for Social and Economic Change (ISEC), Nagarbhavi, \\ Bengaluru - 560072, Karnataka, India \\ 2Professor and Guide, Institute for Social and Economic Change (ISEC), \\ Nagarbhavi, Bengaluru - 560072, Karnataka, India
}

\begin{abstract}
The modern urban economies, in struggle to keep up with the pace of economic growth are suffering from issues of sustainability in transportation, imposing huge costs on the economy. Major reasons for the unsustainability in transportations can be listed as, a) issue of accessibility, b) lack of efficiency and c) diminishing air quality. This paper tries to evaluate these issues for megacities of India from dimensional principles of sustainability. The paper tried to evaluate the indicators of sustainability by adopting the famous three-dimensional principles to the major mega cities of the country. The findings from this paper are quite interesting to note that, the major mega cities are suffering from unsustainable transport system. To have a deeper look, Bengaluru, emerging mega city of Karnataka, is analysed by bringing new dimension called, institutional sustainability. By evaluating, economic, social, environmental and institutional sustainability with relevant benchmarks, the result showed that, in all respect mega cities of India and more specifically, Bengaluru city is experiencing unsustainable growth of transport sector which needs urgent attention of the policy makers.
\end{abstract}

Keywords: Economic, Environmental and Institutional Sustainability, Indicators, Metropolitan Cities, Social

\section{Introduction}

A sustainable urban set up is elusive without sustainable transportation (Munira and Santoso, 2017). Sustainability of the area depends on the efficiency of its transport system, which refers to how efficiently mobility concerns are addressed. This will determine the economic vitality of a city, by attracting employment, people and income. The modern urban economies, in struggle to keep up with the pace of economic growth are suffering from issues of sustainability in transportation, imposing huge costs on the economy. Authors around the world have examined how unsustainable urban transportation may decrease the overall economic growth in the world. Some of the major reasons for the unsustainability in transportations can be listed as, a) issue of accessibility, b) lack of efficiency and c) diminishing air quality. This paper tries to evaluate these issues for cities of India.

Before evaluation of the sustainability issues of the urban transport, it important to understand at the outset, the driving forces behind the unsustainability. At the macro level, it is commonly observed that, cities are the hub of employment and ever-increasing per capita income. According to World Urbanization report (2015) cities are home for more than half of the world population and contributor of 60 percent of world's GDP (World Bank, 2013), which has created unprecedented demand to travel more so in private transport, causing negative externalities like time loss, air pollution and health impacts on the economy. The impact of externalities differs from country to country.

\footnotetext{
*Email: vijaya@isec.ac.in

\#This is the revised and modified version of the article, presented in the $4^{\text {th }}$ International Conference on "Economic Growth and Sustainable Development: Emerging Trends" SDMIMD, November, 2018.
} 
The nature of urban road transport of developing nations is quite different from that of developed countries as cities of the developed countries encounter more or less with homogenous private transport whereas in the developing countries, the transport system is heterogeneous in nature (Kiran \& Verma, 2016). This heterogeneity has different implications on the economic system, which needs a special attention. The indicators and formulas developed for the study of homogeneous traffic structure of the developed countries fails to address the problems and issues of the developing nations. Though there are many attempts across the world and in India, which tried to evaluate the existing indicators in the literature for the developing country's transport system, a comprehensive sustainable indicator urban transport system is still needs research.

The concept of sustainability started attracting the attention of the policy makers, academicians in the late 1980 's, which mainly addressed the environmental concerns. But there are multi-dimensional definitions of sustainability in literature. From economic perspective the term 'sustainability' was defined mainly focusing at maintaining and guaranteeing the consumption possibility for present and future generation, which was highly debated definition due to its narrower scope (Arnott \& Small, 1994). With the publication of Brundtland commission report in 1987, with the economic sustainability of the urban transport, other dimensions like environment and social concerns are also added to arrive at comprehensive sustainable transportation. In most of the recent literatures, these three dimensions are popularly referred as 'three pillars of sustainability', but transport sustainability should also have the fourth dimension called Institutional sustainability which constitute one of the major components in achieving sustainability aiming for better governance of the sector.

\section{Objective of the Paper}

More importantly, this paper tries to evaluate the sustainability dimensions in Indian metropolitan cities by adopting certain benchmarks (targets). Since most of the indicators' benchmarks are highly subjective in nature, we tried to adopt few indicators for which relevant targets are available in existing literature.

\section{Organization of the Paper}

The paper is organized into four sections. In the first section, the papers begin with the conceptualization of sustainability in urban transport system and also brings out the literature review of the indicators evolved to address the pillars of sustainability adopted in urban transport across the globe and in India. The second section, involves selection of suitable indicators of sustainability with relevant benchmarks. The third section, brings out a comparative analysis of the sustainability issues in the major metropolitan cities of the country at large and Bengaluru in particular. The conclusion section, provides the summary and comments on the issue under study.

\section{Section I}

\subsection{Sustainability and Urban Road Transport}

Though 'sustainable transportation system' is based on the notion of sustainable development, there are multiple definitions for the concept. In fact, the term 'sustainable development' was first coined by the World Conservation Strategy (WCS) in 1980 (World Bank, 1996) but most of the definitions in the literature are based on Brundtland commission report in 1987. One such definition is given by WBCSD (2004) which state that, 'sustainable transportation or sustainable mobility is the ability to meet present society's need to move freely, gain access, communicate, trade without compromising the same for the future'. This definition highlights the original theme of sustainable development that is intra and inter-generational equity. In the urban transport system, the principles of intra and inter-generational equity highlights importance of providing adequate, safer, affordable, convenient and 
efficient mode of transportation to both present and future generations.

On the same parlance, the definition of Zietsman and Rilett (2001) states that, sustainable transportation attempts to address economic development, environmental concern and social equity of current and future generations. This definition highlights the importance of three dimension of sustainable development in the transportation system. CST (2002), on the other hand, State that, sustainable urban transport which:

a. Allow the basic access needs of individuals and societies to be met safely and in a manner consistent with human and ecosystem health, and with equity within and between generations.

b. Is affordable, operates efficiently, offers choice of transport mode, and supports a vibrant economy.

c. Limits emissions and waste within the planet's ability to absorb them, minimizes consumption of non-renewable resources, limits consumption of renewable resources to the sustainable yield level, reuses and recycles its components, and minimizes the use of land and the production of noise.

On a whole, all these definitions can be summarised as, sustainability in transportation system must ensure economic efficiency, environmental stewardship and social equity which are the main principles of sustainability. Since majority of studies accepts and highlights the importance of these principles, it is relevant to have a conceptual clarity of these dimensions.

\subsubsection{Dimensions of Sustainability}

There are various studies which conceptualized the notion of sustainability from different perceptions. The most popularly adopted model is from World Bank (1996) which provided the three dimensions of sustainable transportation (Figure 1).

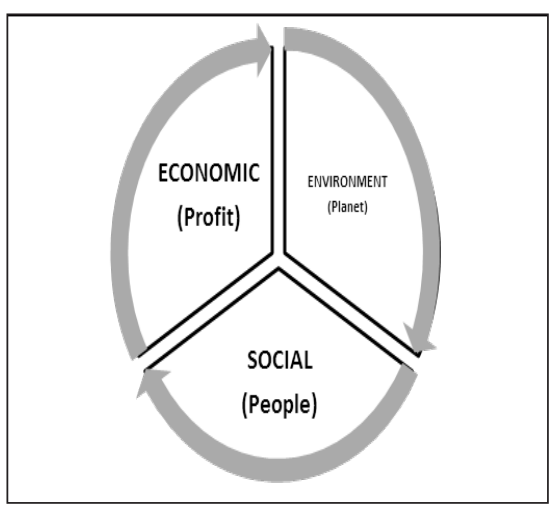

Source: IISD (1999)

Figure 1. Dimensions of sustainability.

- Economic sustainability of transportation which ensures efficiency in the transportation network, with reduced congestion level. The economic dimension of the transportation brings out the efficient use of the resources with lesser burden on the economy, which ensure profit to the overall economy. World Bank (1996) suggests the economic sustainability in terms of vehicle fleet, transportation network and public transportation system.

- Social sustainability of transportation emphasis on equity and affordability (Ahmed et al., 2008, Keyon et al., 2002). This includes accessibility issue of different class of the society. The prioritization of public transportation, especially looking at the affordability of low income class of the society is the main concern of the social sustainability.

- Environmental sustainability relates to reduced negative externalities due to transportation and increased quality of living. Environmental dimension of transport stress for cleaner environment with lesser and optimum utilisation of energy and reduced pollution levels. Loo (2002) analysed that, as per WHO in 1999, vehicles are responsible for almost 90-95 percent of $\mathrm{CO}_{2}$ and lead and 60-70 percent of nitrogen oxide and hydrocarbon emissions in city centres. This state the need to attain environmental sustainability as a priority objective to achieve sustainable urban transportation system. 
As stated earlier, in most of the literature on sustainability, these three principles are considered as major goals of sustainable development. But, comprehensive transport sustainability must also include fourth dimension called Institution.

- Institution sustainability relates to the issue of governance in transport. The concept of governance looks at the micro-level issues of transport, concerning to the city administration and planning departments. It mainly addresses the issue of proper management of traffic signals, maintenance of road pavements, pedestrian paths and so on. This dimension becomes more relevant in case of developing countries like India where improper management of transport sector is considered as one the main causes of unsustainability.

\subsection{Empirical Literature Review on 'Approaches of Urban Transport Sustainability'}

From the conceptualisation, it is clear that sustainability calls for integration of these dimensions. Since the paper is looking at this integration, it is important to look at the studies conducted at different parts of the world. Hence, the literature review mainly concentrated on empirical evidences.

There is huge literature on the initiatives taken on developing and quantifying the performance of transportation (OECD, 2002; Litman, 2011). Most of these studies are carried out in the developed part of the world and very less number in developing countries. Some of the important studies which considered the three dimension of sustainability are:

\begin{tabular}{|l|l|}
\hline Studies & Findings \\
\hline Cape Town Study (2006) & Transit oriented development is essential for sustainable economies. The study emphasised on public transportation. \\
\hline CST study (2002) on Canadian Transport & Developed Sustainable Transportation Performance Indicators (STPI). \\
\hline EEA (2010) & Transport and environment from three dimensions of sustainability. \\
\hline Nicholas et al. (2003) Study of Lyons & Three-dimensional sustainable development. \\
\hline Ramani (2009) on Texas & Multi-criteria decision-making approach to form sustainability development indicators. \\
\hline WBCSD (2004) & Sustainable mobility of world cities at three dimensions. \\
\hline Shaheen (2016) & Sustainability Performance indicators by looking at economic, social, environmental dimensions. \\
\hline Dock et al (2012) & PacScore local accessibility metric system for Pasadena, California. \\
\hline Hale (2011) & Broader set of indicators based on three-dimensional approach of sustainability. \\
\hline Jeon et al (2008) & Multi criteria sustainability approaching using performance indicators and evolved a composite sustainability index. \\
\hline KOTI (2011) & Developed Green Growth Index, looked at environmental aspects of Korean cities. \\
\hline Arcadis (2018) & Developed Sustainable urban mobility index for 100 cities evaluating 23 indicators less than three-dimensional \\
& approach. \\
\hline Indian Studies & \multicolumn{2}{|l}{} \\
\hline CSTI (2007) & Three-dimension approach to cities of India. \\
\hline Reddy and Nathan (2011) & Multi-view Black-box framework for integrating socio-economic and environmental aspects for Mumbai city. \\
\hline
\end{tabular}

Reviewing the literature on the dimensions of sustainability, it can be pointed out that, most of the studies considered three dimensions of sustainability based on their scope of study, but in the field of transportation, it becomes essential to evaluate the fourth dimension, namely institutional sustainability, to arrive at a proper sustainability indicator. Institutional dimension of sustainability in transport sector aims for better governance by providing safe and secure mobility to the society.

\section{Section II}

\subsection{Selection of Suitable Indicator and Setting Benchmarks (Targets)}

Indicators are the tools which measure the progress or growth of defined goal or objectives. They can be defined in terms of goals, objectives, targets and thresholds. Indicators should be carefully selected to provide useful information (USEPA, 2008). Choosing indicators often involves trade off. A small 
set of indicators may use available data which is more convenient (OECD, 2016) for analysis but it may overlook the important impacts. A large set of indicators can be more comprehensive but it needs excessive data collection and analysis (Litman, 2011). Hence a cautious selection of indicators is needed to arrive at somewhat comprehensive indicators.

There are many guidelines given in the literature in selecting the indicators, but most popularly accepted indicators are given by OECD (2008). They include: acceptability, accuracy, affordable, appropriate level of detail, benchmark oriented, measurable, relevancy, sensitive and comprehendible (Houghton, 1998) (Description of each criteria is in Appendix 1).

\subsection{Indicators and their Targets}

Conventional evaluation techniques of transportation system focused on the financial and economic aspects of the investment. But to evaluate sustainable transportation, abroadermethodology is required, which can cover the issues of social equity and environment (Ramani et al., 2009). But a mere analysis of indicators will not aid for policy decisions. A good criterion needs to have a benchmark, to which the indicators can be compared (Levett, 1998). For this, current paper tried to adopt the three-dimensional approach of sustainability and their relevant benchmarks.

\subsubsection{Economic Sustainability Indicators and their Targets}

Economic sustainability looks at the efficiency part of transport sector. Though in conventional economics, transport sector evaluation was mainly done for investment purpose by conducting on cost and benefit analysis or feasibility analysis, but such analysis is considered as narrow in scope. Economic sustainability has to consider both cost and efficiency of the sector (Table 1).

Table 1. Economic sustainability indicators of transportation

\begin{tabular}{|l|l|l|}
\hline \multicolumn{1}{|c|}{ Indicator } & \multicolumn{1}{c|}{ Description } & \multicolumn{1}{c|}{ Benchmark/Direction } \\
\hline Travel time index & $\begin{array}{l}\text { Average time taken to } \\
\text { reach a destination }\end{array}$ & $\begin{array}{l}\text { Less is better (within } 30 \\
\text { min) (Arcadis, 2018) }\end{array}$ \\
\hline $\begin{array}{l}\text { Per capita vehicular } \\
\text { density }\end{array}$ & $\begin{array}{l}\text { Number of vehicles per } \\
1000 \text { population }\end{array}$ & Lesser is sustainable \\
\hline Accessibility index & $\begin{array}{l}\text { Average distance to } \\
\text { nearest bus stop }\end{array}$ & Within 2 kms is sustainable \\
\hline
\end{tabular}

\subsubsection{Social Sustainability Indicators and Targets}

Social sustainability addresses the issue of affordability and equity. Transportation affordability refers to the average expenditure of a household on transport sector. It is advisable that the travel cost should not be more than 20 percent of total household income (US Bureau of Labour Statistics, 2010). Even the prioritisation of public transport in the area will address the social concerns (Table 2).

Table 2. Social sustainability indicators

\begin{tabular}{|l|l|l|}
\hline \multicolumn{1}{|c|}{ Indicator } & \multicolumn{1}{c|}{ Description } & \multicolumn{1}{c|}{ Benchmark/Direction } \\
\hline $\begin{array}{l}\text { Transport } \\
\text { expenditure }\end{array}$ & $\begin{array}{l}\text { \% of household income } \\
\text { spend on travel }\end{array}$ & Should be less than 20\% \\
\hline $\begin{array}{l}\text { Share of public } \\
\text { transport }\end{array}$ & $\begin{array}{l}\text { Number of people opting } \\
\text { for buses }\end{array}$ & $\begin{array}{l}\text { Advised to have more } \\
\text { than 50\% of population } \\
\text { (USEPA, 2008) }\end{array}$ \\
\hline
\end{tabular}

\subsubsection{Environment Sustainability Indicators and Targets}

This dimension aims for cleaner environment with lesser and optimum use of fuel resources and reduced pollution levels. It is highlighted that transport sector is the biggest consumer of world energy (IEA, $2011 \& 2015$ ) which brings out the fact that, it is second dominant source of pollution.

Table 3. Environmental sustainability indicators

\begin{tabular}{|l|l|l|}
\hline Indicator & Description & Benchmark/Direction \\
\hline $\mathrm{CO}_{2}$ Emission & $\begin{array}{l}\text { Growth of } \mathrm{CO}_{2} \text { emission from } \\
\text { transport sector }\end{array}$ & Lesser value is better \\
\hline Air quality level & $\begin{array}{l}\text { Average of pollutants in the } \\
\text { area }\end{array}$ & $\begin{array}{l}0-99 \text { index is } \\
\text { satisfactory. }\end{array}$ \\
\hline Fuel consumption & $\begin{array}{l}\text { Use of petrol and diesel by } \\
\text { transport }\end{array}$ & Lesser value is better \\
\hline
\end{tabular}

In practice, it is often not feasible to apply all the indicators described in (Table 3), due to data restrictions. When these indicators are applied for India's transport sector, data has become a major issue to construct the index. Later in this paper, such indicators are prioritised whose data is available and can be applied.

\subsection{Indicators used in the Paper}

In evaluating the indicator of sustainable transport, most of the data requires the primary survey or primary data collection. Since the present paper relies more on 
the secondary data available, the indicators are selected based on two criteria:

a. Availability of relevant data for all metropolitan cities of the country.

b. Indicators with standard target are available in the existing literature.

Based on these two criteria, the present paper selected one indicator in each dimension (Table 4).

Table 4. Relevant indicators and their targets

\begin{tabular}{|l|l|}
\hline Indicators & Benchmarks or Target or standards \\
\hline Economic Sustainability Indicator \\
\hline Travel time index & $\begin{array}{l}\text { More than } 30 \mathrm{~min} \text { for } 40 \mathrm{kms} \text { of travel is } \\
\text { unsustainable }\end{array}$ \\
\hline Social Sustainability Indicators \\
\hline Priority of public transportation & $\begin{array}{l}\text { At least } 50 \% \text { of total population should be } \\
\text { using public transportation }\end{array}$ \\
\hline Environment Sustainability Indicators \\
\hline Air quality levels - RSPM level & Above $60 \mathrm{ug} / \mathrm{m}^{3}$ is harmful. \\
\hline
\end{tabular}

The paper tries to examine the sustainability issues of major metropolitan cities of the country and more specifically considering Bengaluru city in particular.

\section{Section III}

\subsection{Evaluation of Sustainability Dimensions of Selected Metropolitan Cities}

India is home for major metropolitan cities of the world like Mumbai, Delhi, which are considered as economic growth centres of India in terms of their contribution to GDP, urban sprawling, employment creation, vehicular growth etc. These cities are not only experiencing a positive impact of economic growth on the vehicular growth but suffering from current traffic woos.

According to Census 2011 data, five major metropolitan cities are selected for the study, which are considered as top five populous cities and these cities also have highest vehicular population among other 53 million plus cities. In the (Table 5), these cities are listed with their geographical area and road network data.

Table 5. Details of major metropolitan cities

\begin{tabular}{|l|c|c|c|}
\hline Metropolitan city & $\begin{array}{c}\text { Population } \\
\text { (2011) }\end{array}$ & Area (sq kms) & $\begin{array}{c}\text { Road length } \\
\text { (kms) }\end{array}$ \\
\hline Mumbai & $18,414,288$ & 603.4 & 2000 \\
\hline New Delhi & $16,314,838$ & 1489 & 28,500 \\
\hline Kolkata $^{1}$ & $14,112,536$ & 205 & 1850 \\
\hline Chennai & $8,696,010$ & 426 & 2847 \\
\hline Bengaluru & $8,499,399$ & 709 & 3000 \\
\hline
\end{tabular}

Source: Respective city's corporation websites and census 2011 and 2001.

It is well known fact that, Mumbai and New Delhi tops among the metropolitan cities of the country in terms of population. Since the data relates to only 2011 census, Bengaluru ranks last in terms of population, but in recent population estimates by various agencies state that, the city has over-crossed Chennai city and is home for more than 10.41 million populations and is estimated to be 15 million by 2030 (UN, 2017). Another important fact to notice is that, compared to Chennai, Bengaluru has quite large road network, but it is not in symmetry with the area and population of the city, which may be one of the driving forces of unsustainable transportation in the city.

To evaluate the status of road transport in these cities, the vehicular density these cities are analysed for different years (Figure 2).

It is observed from the data that vehicular growth is not uniform across all cities. Certain cities have slow growth of private vehicles due to pre-existing mass transit like in Mumbai and Kolkata. But certain major metropolitan cities like Bengaluru and Chennai are witnessing tremendous vehicular boom in recent times due to lack of adequate mass transportation services, increasing economic concentration of industries and service sectors, economic migration, changing urban life styles.

\footnotetext{
${ }^{2}$ The city is selected mainly because of its highest population and historical importance in transport sector.
} 


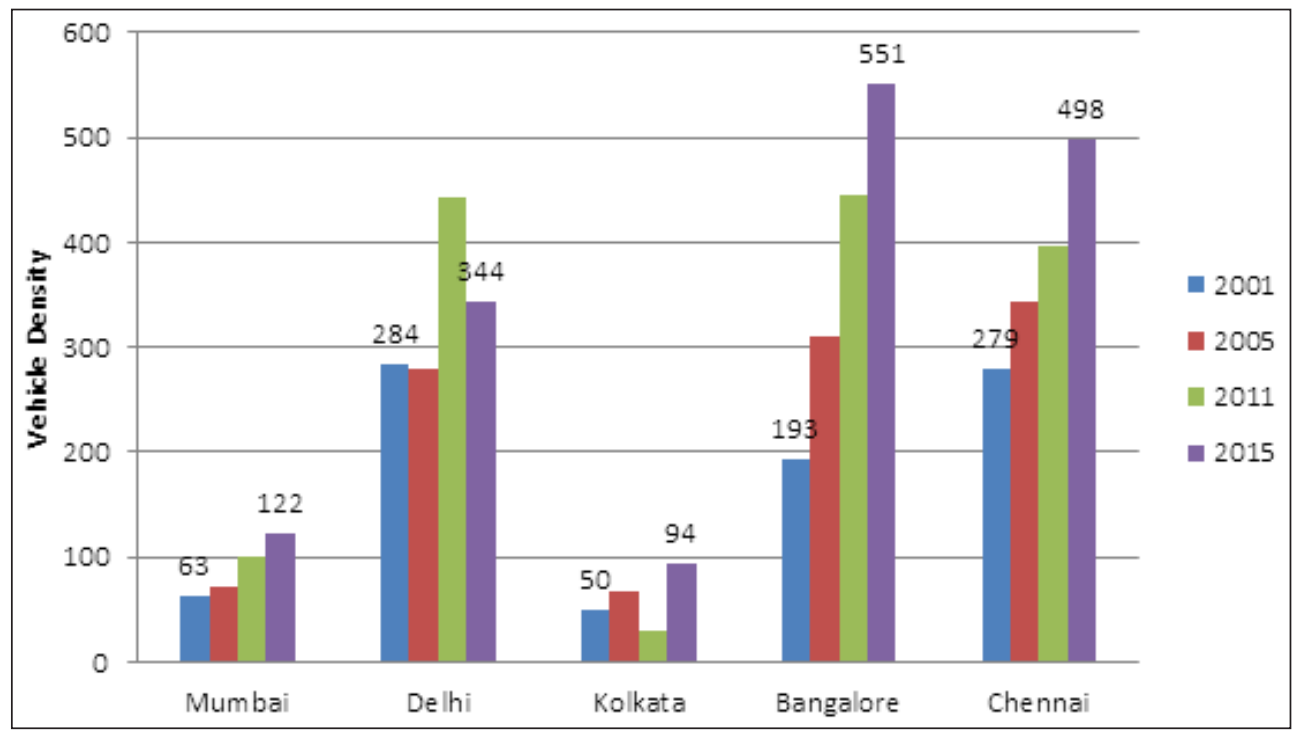

Source: Author's analysis based on MoRTH of various years

Figure 2. Vehicular density of major metropolitan cities.

\subsection{Economic Sustainability Indicator: Travel Time Indicator}

The travel time indicator relates to the average time taken by the commuter to travel a distance of $40 \mathrm{kms}$. The standard average time required to travel by taking average speed of $40 \mathrm{~km} / \mathrm{h}$ is around 30 minutes (Arcadis, 2018).

Table 6. Travel Time indicator and cities

\begin{tabular}{|l|c|}
\hline Metropolitan city & Travel Time Indicator (in min) \\
\hline Mumbai & 58.44 \\
\hline New Delhi & 55.40 \\
\hline Kolkata & 65.53 \\
\hline Chennai & 45.56 \\
\hline Bengaluru & 52.44 \\
\hline
\end{tabular}

Source: Numbeo, 2018.

By considering the travel time indicator, it is evident from the (Table 6) that, all the cities have crossed the standard average time of travel indicating inefficiency in their travel. Kolkata has highest travel time among all other cities, but the interesting fact to notice in the (Table 6) is that, after major three metropolitan cities, Bengaluru city which got the position of metropolitan very recently has almost 52.84 minutes spent for travel, which is on par with national capital (55.40).

\subsection{Social Sustainability Indicator: Priority of Public Transportation}

Priotisation of public transport has been considered as most sustainable mode of transportation. It is advocated that, minimum half of the population of the area should use the public transportation for more sustainable mobility. This helps for conservation of fuel resources and lesser pollution in the environment (Table 7).

Table 7. Share of public transportation in cities

\begin{tabular}{|l|c|}
\hline \multicolumn{1}{|c|}{ Metropolitan city } & $\begin{array}{c}\text { Share of public } \\
\text { transportation (\%) }\end{array}$ \\
\hline Mumbai & 13 \\
\hline New Delhi & 21 \\
\hline Kolkata & 22 \\
\hline Chennai & 19 \\
\hline Bengaluru & 20 \\
\hline
\end{tabular}

Source: Census, 2011.

Among the considered metropolitan cities, comparatively New Delhi and Kolkata are in better position than other cities where the people using public transportation is less than 20 percent, which clearly indicate social unsustainability. 


\subsection{Environmental Sustainability Indicator: Average Air Quality Levels}

The environmental sustainability relate to efficient use of energy and clean air quality. Since the energy data at the city is inadequate hence kept out of this paper. Air pollution is considered as world's leading health risk by World Bank (2016). Due to diseases related to air pollution, more than 5.5 million people die prematurely around the world (GBD, 2013, Collaborators, 2015). Major air pollution related illness is lung cancer, respiratory infections, chronic obstructive pulmonary diseases like bronchitis and emphysema. A study by World Bank (2016) considered exposure to air pollution has become fourth main fatal health risk worldwide. Some of the major damaging pollutants found are $\mathrm{PM}_{2.5}$ and $\mathrm{PM}_{10}$. These pollutants are found at a high level in urban regions, where there is combination of people, vehicles, dirty fuels and constructions etc.

The fatal risk of air pollution has costed 8.5 percent of GDP to India, which majorly attributed to the pollutants like $\mathrm{PM}_{10}$ in 2013 (World Bank, 2016) and air pollution is considered as third fatal risk factor of death in low and middle income country and India is not free among them. As it is well known fact that air pollutants are severe in urban areas, cities of India are also suffering from air pollution damages. Among them, few metropolitan cities are at high risk. Rather than any other pollutants like $\mathrm{SO}_{2}, \mathrm{NO}_{2}$, it is $\mathrm{PM}_{10}$ which has crossed the prescribed standard level in metropolitan cities (Figure 3).

The level of $\mathrm{PM}_{10}$ whose standard is $60 \mathrm{ug} / \mathrm{m}^{3}$ has been crossed in all the major metropolitan cities, which indicate highly unsustainable transport system. Due to decreasing level of air quality at the major metropolitan cities, the health related risks are increasing in recent years.

From the analysis it is evident that each city is in the grip of unsustainable transport system causing severe traffic congestion and which has become an emerging urban phenomenon.

\section{Sustainability and Bengaluru}

It is common to perceive that in major metropolitan cities of the developed countries, the negative impact of transportation outweighs the positive effects, which resulted in unsustainable urban transport. But, India, being developing country of the world, also suffers from same trend of unsustainable urban transport majorly in metropolitan cities. Cities like Delhi and Mumbai were considered to be mega cities and are prone for unsustainability, but for this list of metropolitan cities, Bengaluru was also added. In this section, the city's sustainability issues are evaluated by considering three dimensions of sustainability.

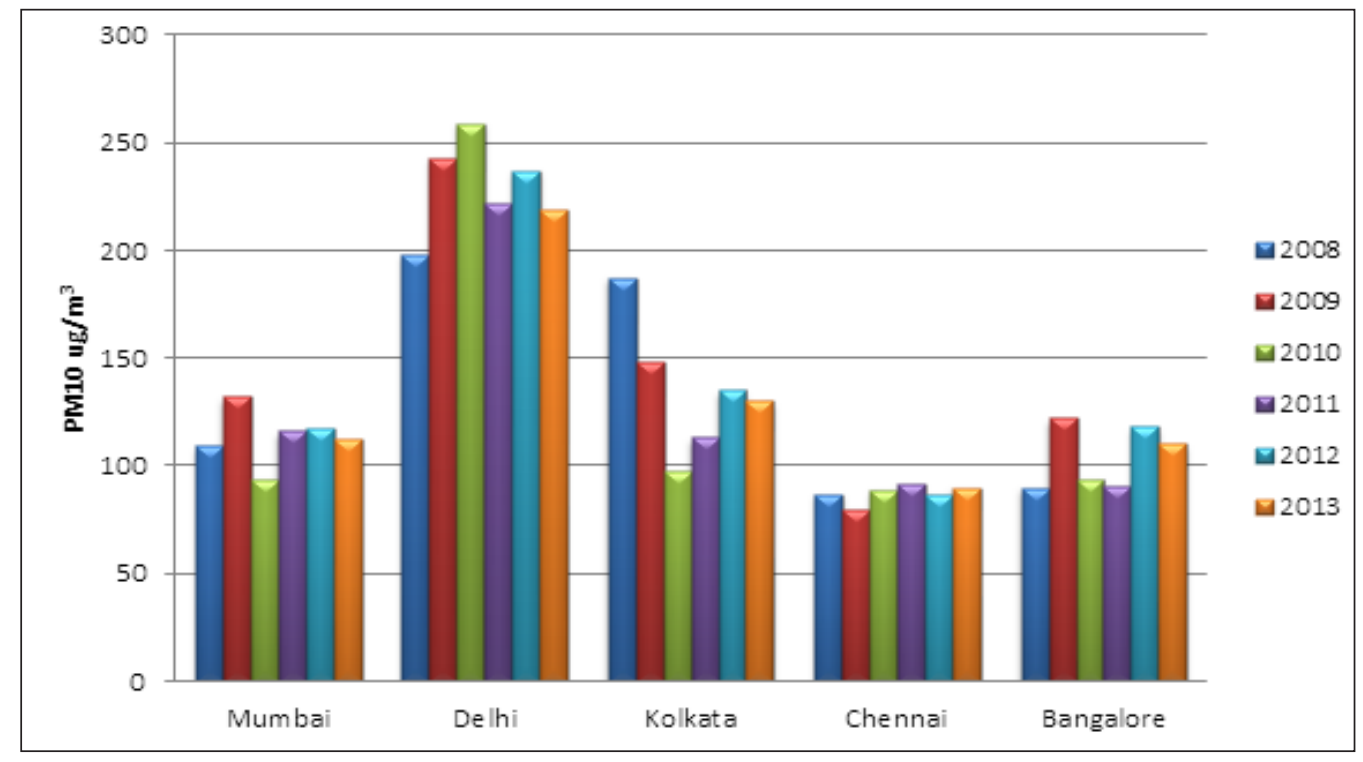

Source: CPCB of various years.

Figure 3. Level of average $\mathrm{PM}_{10} \mathrm{ug} / \mathrm{m}^{3}$. 
In the evaluation of indicators for the city, it is advisable to have a benchmark to compare the issue of unsustainability, but due to non-availability of standard benchmark, the paper adopted the directional analysis of the indicators as suggested by Litman (2011). Hence each indicator is compared with the previous years and their direction is observed to state the results (Table 8).

Table 8. Suitable indicators for Bengaluru study

\begin{tabular}{|c|c|c|c|}
\hline Indicator & Methodology adopted & Indication & Direction \\
\hline \multicolumn{4}{|l|}{ Economic Sustainability } \\
\hline Road density by population & $\begin{array}{l}\text { Total road length } \\
\text { Population }\end{array}$ & It indicates availability of road for population & Higher value is better \\
\hline Vehicular density by road & $\begin{array}{l}\text { Total vehicles } \\
\text { Road length }\end{array}$ & $\begin{array}{l}\text { It measures the vehicle density on available } \\
\text { road }\end{array}$ & Lower is better \\
\hline Vehicular density by population & $\begin{array}{l}\text { Total vehicles } \\
\text { Population }\end{array}$ & $\begin{array}{l}\text { It indicates the motorisation level of the } \\
\text { population }\end{array}$ & Lower is better \\
\hline Private vehicle mobility & $\begin{array}{l}\text { Vehicles Kilometer Travelled (VKT) } \\
\text { of private vehicles }\end{array}$ & $\begin{array}{l}\text { It signifies the dominance of private mode of } \\
\text { transportation }\end{array}$ & Lower is better \\
\hline Public vehicle mobility & VKT of public transport & $\begin{array}{l}\text { This indicate the importance of public } \\
\text { transportation }\end{array}$ & Higher is better \\
\hline \multicolumn{4}{|l|}{ Environmental sustainability } \\
\hline $\mathrm{CO}_{2}$ emission of transport & $\begin{array}{l}\text { Growth rate of } \mathrm{CO}_{2} \text { emission from } \\
\text { transport sector }\end{array}$ & $\begin{array}{l}\text { It indicate the pollution level from transport } \\
\text { sector }\end{array}$ & Lower will be better \\
\hline Air quality level & Average of pollutants in the area & This indicate the quality of environment & 0-99 index is sustainable \\
\hline \multicolumn{4}{|l|}{ Social sustainability } \\
\hline $\begin{array}{l}\text { Share of public transport to total } \\
\text { transport }\end{array}$ & $\begin{array}{l}\text { Public transport } \\
\text { Total vehicles }\end{array}$ & $\begin{array}{l}\text { This indicate the importance given to public } \\
\text { transport }\end{array}$ & Higher is better \\
\hline Public transport density & $\begin{array}{l}\text { Public transport } \\
\text { Population }\end{array}$ & $\begin{array}{l}\text { This indicate the accessibility of public } \\
\text { transport }\end{array}$ & Higher is better \\
\hline Private vehicle density by road & $\begin{array}{l}\text { Total private vehicles } \\
\text { Road length }\end{array}$ & It indicate the personal vehicular density & Lower is better \\
\hline Public vehicle density by road & $\begin{array}{l}\text { Total public vehicles } \\
\text { Road length }\end{array}$ & It indicate the importance of public transport & Higher is better \\
\hline \multicolumn{4}{|c|}{ Institutional sustainability (Governance Issue) } \\
\hline Road condition & \multicolumn{2}{|l|}{ Number of bad roads in the city } & Should be none or least \\
\hline Issue of complainace & \multicolumn{2}{|c|}{ Number of cases filed for traffic violation } & Should be least \\
\hline
\end{tabular}

Source: Author's compilation from UNCSD (1996).

For certain indicators like air pollution, there are standard benchmark available and hence, adopted the same. But, majority of economic, social and institutional indicators lacks a standard yardstick; hence, a comparative analysis is used.

\subsection{Bengaluru and Sustainable Road Transport: City Profile}

The city, not only evolved as a major centre for public sector enterprises, but in the late 1990's, it became a hub for IT sector. Forbes (2017) has designated the city as one of 'The next decade's fastest growing city' which has top $15 \mathrm{MNC}$ of the world. Because of its distant features like increased employment levels and conducive climate, the city has a unique place in India's metropolitan city status. It is the fifth largest metropolitan city in the country, having the growth rate of 10.3 percent (aagr) in its per capita income (2014-15) and is the house of about 10.52 million populations (2014-15). Because of its IT sector and other associated industries, migrating population growth is also increasing at a faster rate. This has led to increase in the demand vehicular population with an annual growth rate of $10 \%$ in 2015 . These factors ranked the city as 
$6^{\text {th }}$ in the world for experiencing worst commuter pain index (IBM, 2011) outranking Delhi ( $7^{\text {th }}$ rank). The city suffers from the loss of around Rs. 3,700 crores annually in terms of man-hour wasted (BMR, 2013), which indicates a clear case of inefficiency of city's transport system. Hence, it is important to evaluate the sustainability issues of the city.

\subsection{Economic Sustainability}

As stated, economic sustainability ensure efficiency in transport sector. This efficiency depends on certain parameters like road length availability, vehicle density and vehicular mobility issues. One of the main parameter which indicates the economic vitality of the area is its per capita income. In this section, PCI of Bengaluru and its vehicular growth is compared to see the relationship.

\subsubsection{Vehicular Growth and Per Capita Income of Bengaluru}

As it is already stated that, Bengaluru is one of the fastest growing metropolitan city of India, it is justified by the increase in per capita income. According to Economic Survey of Karnataka (2014-15) Bengaluru has highest per capita income among all districts the per capita income is growing at 14.12 percent during 2001-16, whereas the vehicles are growing at 10.18 percent. It is clearly indicated that, the growth in per capita income has a positive impact on the vehicular growth (Figure 4).

\subsubsection{Efficiency of Road Infrastructure in Bengaluru}

The economic efficiency of transport sector in Bengaluru is determined by the efficiency of road transport, as road forms the only mode of transport within the city. Before analyzing the indicators, it will be apt to know the road network outline of the city.

\subsubsection{Road Network of Bangalore}

Bangalore has grown into radial city with 9 road corridors forming the principal radial arms, with concentric orbital corridors. NH7, NH4 (part of North South Corridor and Golden Quadrilateral, respectively) and $\mathrm{NH} 209$ pass through Bangalore forming five important radial roads within the Bangalore Metropolitan Area. Bangalore has also major arterial roads such as, Mysore road, Kanakapura Road, Bannerghatta Road, Magadi Road and Sarjapura Road which connect Bangalore City to other rural

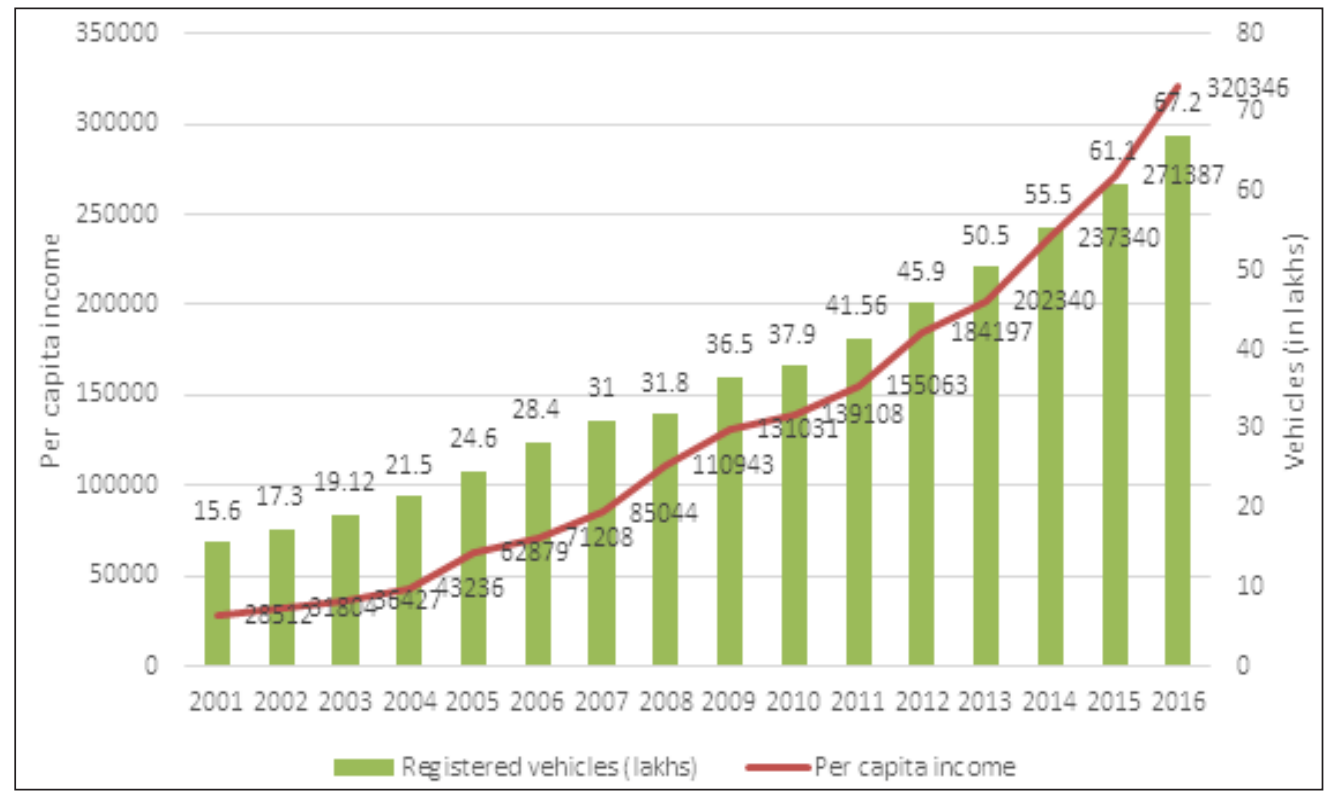

Source: Author's analysis based on RTO, Bengaluru and Karnataka Economic survey data

Figure 4. Per capita income and vehicular growth in Bengaluru. 
areas. Developed as a radial town, Bangalore does not have a strong circumferential road system, except for the Outer Ring Road, despite development of the intervening space between the corridors.

The primary network, $500-600 \mathrm{~km}$ out of the total road length of $3,000 \mathrm{~km}$, includes 10 state and/or national roads, most of them radial. An Outer Ring Road (62 km, completed in 2002) plays little role in urban transport, carrying mainly the long-distance through traffic. An Intermediate Ring has been constructed in fragments (e.g. south-east between Koramangala and Airport Road). Generally, the road network is underdeveloped in terms of size, structure, continuity and connectivity. The city roads were laid out in the 1940s, when Bangalore had a population of less than half a million. The land development process preceded motorization, and in fact inhibited it later. The primary roads (Outer Ring Road and Bangalore-Mysore Toll Road except) are merely $25 \mathrm{~m}$ wide, or less.

A newly added road infrastructure to the city is Namma $\mathrm{Metro}^{3}$, a BMRCL project, with daily ridership of 350,000 (BMRCL, 2017) is still to complete its entire project. As on 2018, metro is operating at two lanes connecting Byappanahalli to Mysore road covering $18.22 \mathrm{kms}$ and Nagasandra to Yelachenahalli with $24.20 \mathrm{kms}$, hence in total, $42.42 \mathrm{kms}$ is covered by the project (BMRCL, 2014).

With the information of the road network, it will be relevant to understand the efficiency of it, in this section.

a. Per capita road length: This indicator expresses the availability of road length for the population. Since there is no standard benchmark to measure the road length for the population, we will observe the growth of per capita road length over the years. From the (Table 9), we can infer that the per capita availability of road length for the population of
Bengaluru city is decreasing over time. The road length in 1971 was $0.93 \mathrm{kms}$ for 1000 population, which has decreased to $0.2 \mathrm{kms}$ in 2016 . Interesting fact to be noted here that, there is a need to increase the urban road infrastructure as the city is growing in its size. The city was just $101.41 \mathrm{sq} \mathrm{kms}$ in 1961 has grown to $709 \mathrm{sq} \mathrm{kms}$ by the end of 2015. This clearly signifies the need of improving the road structure in the city.

Table 9. Road infrastructure efficiency in Bengaluru

\begin{tabular}{|c|c|c|c|}
\hline Year & $\begin{array}{c}\text { Per capita road } \\
\text { length }\end{array}$ & $\begin{array}{c}\text { Vehicle density by } \\
\text { road }\end{array}$ & $\begin{array}{c}\text { Vehicle density by } \\
\text { population }\end{array}$ \\
\hline 1971 & 0.937 & 69959 & 65.6 \\
\hline 1981 & 0.543 & 120210 & 65.2 \\
\hline 1991 & 0.402 & 398404 & 160.3 \\
\hline 2001 & 0.357 & 859101 & 307 \\
\hline 2011 & 0.234 & 1527199 & 358 \\
\hline 2018 & 0.239 & 2485650 & 595.6 \\
\hline
\end{tabular}

Source: Author's analysis based on Census Karnataka, RTO Bengaluru, BMR.

b. Vehicular density by road: This signifies the vehicle density on the available road length. As with the case of other indicator, this also lacks a benchmark and hence we observe the trend over years. Clearly from the (Table 9), the number of vehicles on 1000 kms of road length has nearly increased over 43 times (1971-2016), by accentuating the pressure on the road structure. This signifies unsustainable growth of road transport in the city.

c. Vehicle density by population: This mainly points at the pattern of ownership levels in the city. The vehicle ownership has dramatically increased over time in the city from 65 vehicles for 1000 population in 1971 to almost 595 vehicles by 2016, which has out beaten the national capital Delhi (395 vehicles).

To give more clear understanding of the efficiency of road sector, a graphical representation is provided in the (Figure 5). The chart signifies the meagerness in

${ }^{3}$ Due to data unavailability on metro, it is avoided in further analysis in the paper. 


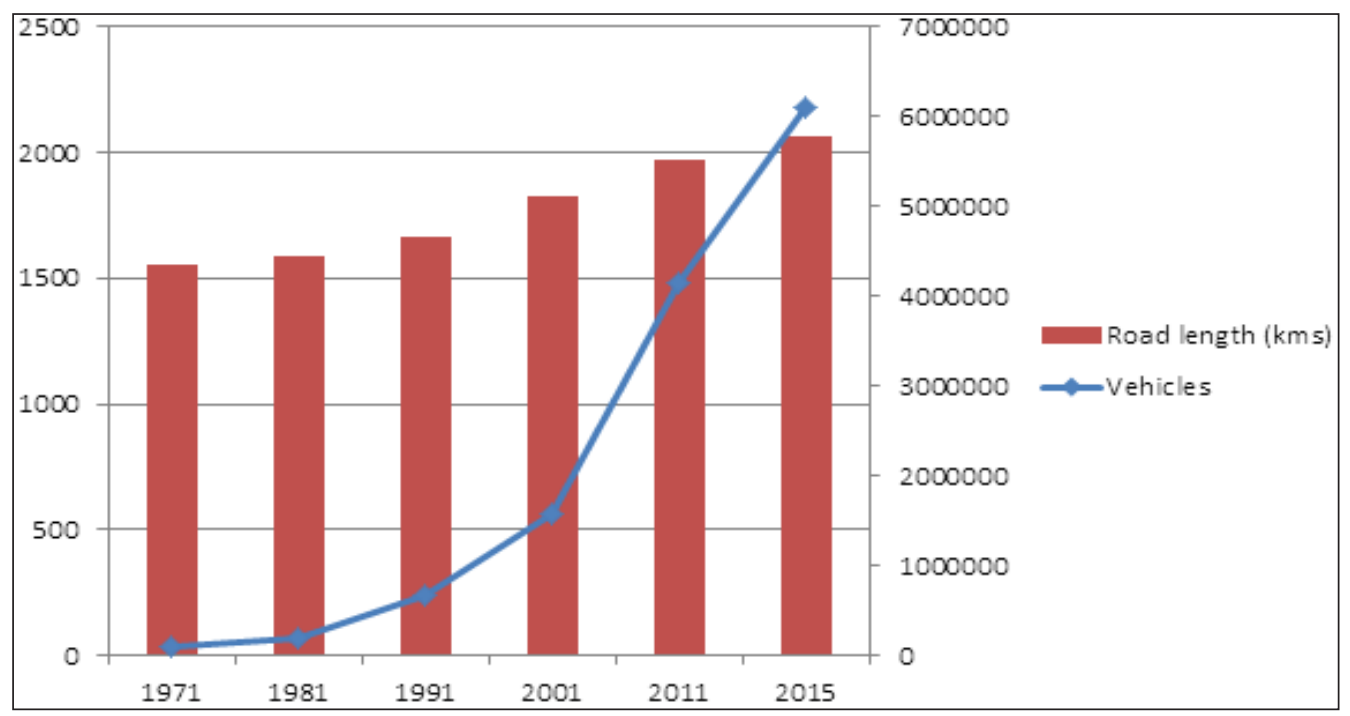

Source: RTO and CDP, Bengaluru.

Figure 5. Road length and vehicles growth levels.

the growth of road length in the city as compared to the leaping growth trend of vehicular population.

\subsubsection{Mobility Concern of the City}

The mobility issues of the transport sector explain the dominance of a transport mode. A usual method of calculating the passenger mobility is through Passenger Kilometers Travelled (PKM). Since the data pertaining to the indicator (Passenger mobility or PKM) requires the primary collection of data, it is held outside the interest of the paper and will be pursued in the future analysis. Apart from PKM, another important indicator of mobility is VKT.

Vehicle Kilometer Travelled (VKT): This parameter measures the mobility preferences in the study area. The standard method of calculating VKT is given by IRC (1990) by multiplying total vehicles traveling and their distance travelled. The major issue in the calculation of VKT is that it differs from vehicle-wise, locationwise and purpose-wise, hence requires primary survey. Though it is based on primary data, for the paper sake, we have hypothized the VKT calculation and presented for both private and public sector. This hypothesis includes the load factor ${ }^{4}$ assumption adopted and modified from Reddy and Nathan (2011) and IRC (1990). VKT is calculated separately for private transport (Two-wheelers, cars and Jeeps) and public transport $\left(\right.$ Buses $\left.^{5}\right)$ (Figure 6).

From the analysis of VKM for both public and private transport of Bengaluru, it is evident that, the mobility of public transport much lesser than the private. This indicates the movement of private transport is dominating the travel in the city, which is a clear example of unsustainable transportation system. Interesting fact to note in Bengaluru's mode of travel is, more than 75 percent of its total vehicular volume is made of two-wheeler and 12 percent of cars, 3 percent of autos and buses form just 1 percent (RTO, 2018). Cities are no doubt, will be staggered by private mode of transport, but even after the initiation of metro train transport in the city, the share of private transport has not decreased. This can be evidently seen in the motorization level of Bengaluru over the period of 2001 to 2018 in the (Figure 7).

${ }^{4}$ Load factor is the average number of distance travelled by a category of vehicle in a day. Load factor for private transport $=15 \mathrm{kms} /$ day; public transport $=120 \mathrm{kms} /$ day.

${ }^{5}$ Metro train is not included due to data unavailability 


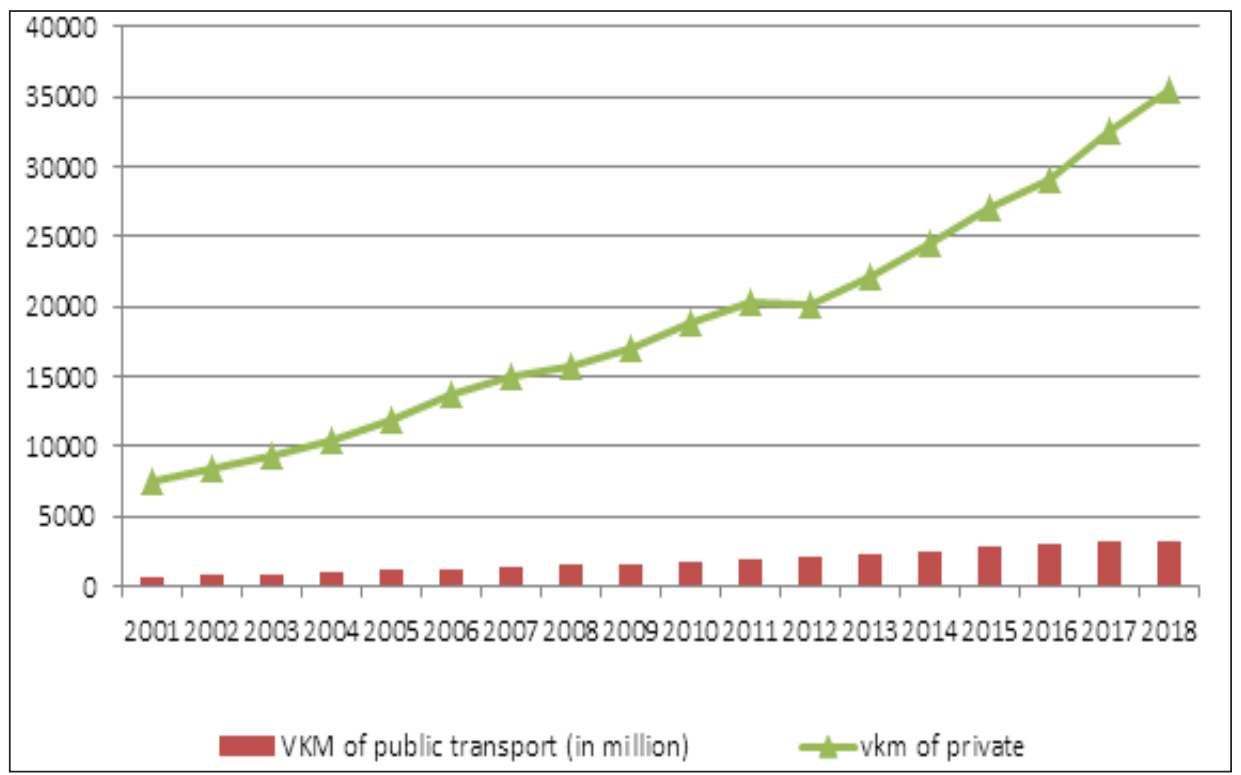

Source: Author's analysis based on RTO data and IRC (1990).

Figure 6. Vehicle kilometer travel by mode.

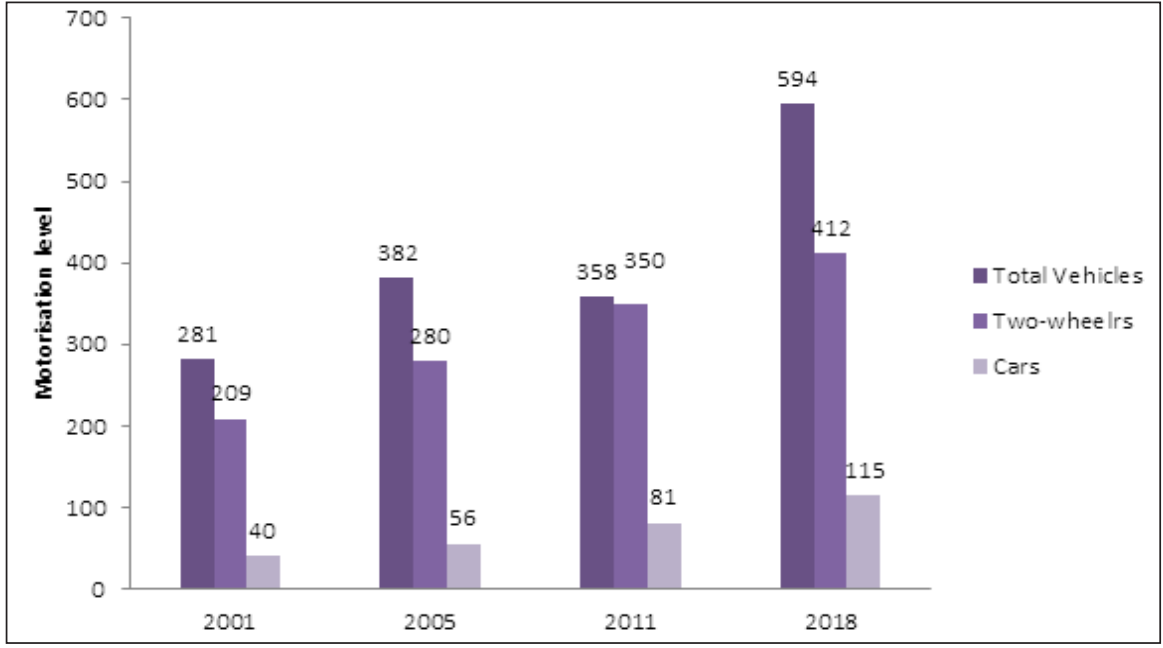

Source: Census Karnataka, RTO Bengaluru.

Figure 7. Motorization level in Bengaluru city.

Based on the (Figure 7), it can be analyzed that the growth of two-wheelers and cars increasing at a high rate. The motorization level of two-wheelers has doubled between 2001 and 2018, whereas in case of cars, it almost increased three times. A decrease in the motorization level in 2011 can be linked to post impact of recessionary trend in the economy.

The public transport in the city has been increasing at a less than one percent rate, which indicates a case for unsustainability in transport sector of the city.

\subsection{Social Sustainability}

The issue of social sustainability related to accessibility, equity and affordability of transport system to the entire society. The accessibility of system is measured by evaluating the efficiency of public transport system (Reddy and Nathan 2008). Prioritization of public transportation has favourable effect on low-income population by increasing their ability to access social and economic opportunities (Sa'nchez, et al., 2003). Since the affordability issue 


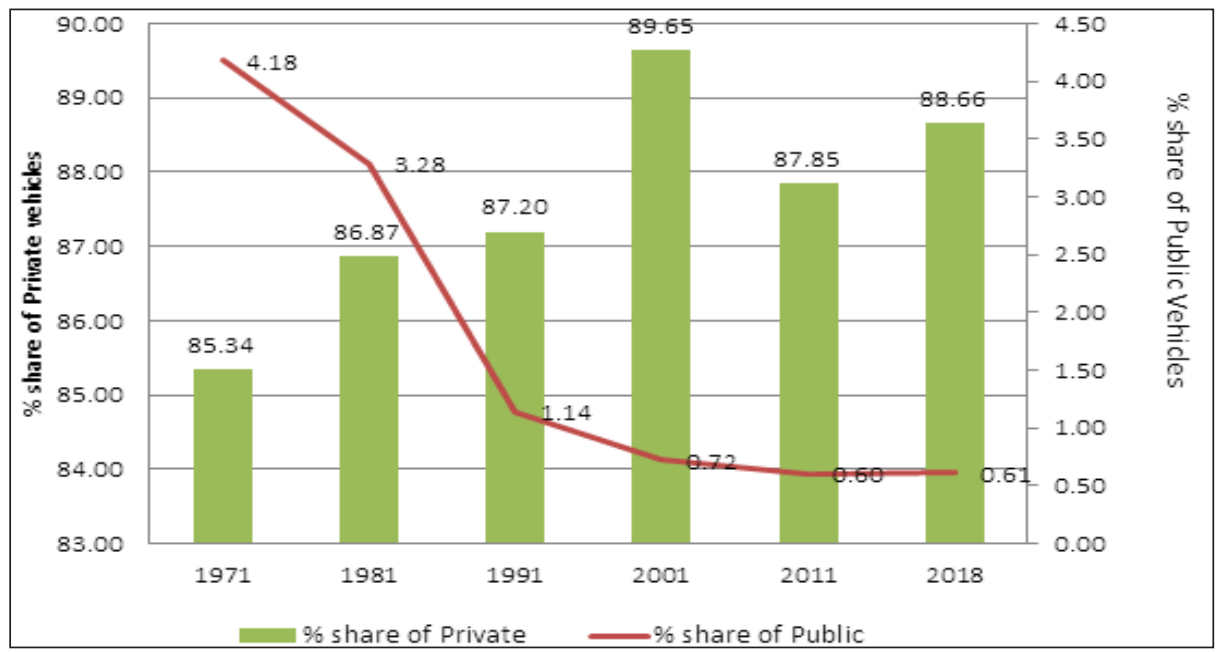

Source: RTO Bengaluru.

Figure 8. Percentage share of mode of transport.

of transport system requires certain data which needs to be collected from the field, it is held outside the scope of this paper.

In this section, we will evaluate the share of public and private mode of transport, which will give an idea about the accessibility issues of society.

Figure 8, it is evident that the share of public transport in the city has been dramatically decreasing over the decade from 4.18 percent in 1971 to 0.61 percent in 20186. But the share of private transport which mainly includes twowheelers and cars has increased from 85.34 percent in 1971 to 88.66 percent in 2018. The decline in 2011 might be linked to recessionary trends in the economy; apart from it the trend is showing upward movement.

\subsection{Environmental Sustainability}

According to the Greenhouse Gas Inventory of Karnataka (KSPCB and Enzen Global Solutions Pvt. Ltd), greenhouse gas emissions as carbon-di-oxide equivalents from the road transport sector in Bengaluru City during the period 2005-06 were around 2.26 million tonnes. Using average figures for fuel consumption and vehicular population for ten-year duration, it was found that emissions have almost doubled from $1997\left(1.01 \mathrm{CO}_{2}\right)$ and are poised to double again in the next ten years, if trends continue (Figure 9).

Among the various pollutants, $\mathrm{PM}_{10}$ contribution is high, next rank goes to Nox. Both pollutants have severe impact on the air quality of the city. Most commonly called as Respirable Suspended Particulate Matter (RSPM) is used to measure the air quality of urban area. Considering the case of Bengaluru, the levels of RSPM are above the standard $\left(60 \mathrm{ug} / \mathrm{m}^{3}\right)$ in most of the places of monitoring. Growth of city during the last decade has contributed to the worsening situation of air pollution in Bangalore.

Karnataka State Pollution Control Board is monitoring the levels of pollutants at seven locations of the city. Graphite India Limited, KHB Indl Area, Peenya Industrial area, Victoria Hospital, Amco batteries and Yeshwanthpur Police Station are monitored using Respirable Dust Sample (RDS) by Conventional method. Four air pollutants viz., Sulphur Dioxide $\left(\mathrm{SO}_{2}\right)$, Oxides of Nitrogen as $\mathrm{NO}_{2}$ and Suspended Particulate Matter (SPM) and Respirable Suspended Particulate Matter (RSPM/ $\mathrm{PM}_{10}$ ), have been identified for regular monitoring at all the locations.

\footnotetext{
${ }^{6}$ This data do not include the Metro trains, as data is not available presently.
} 


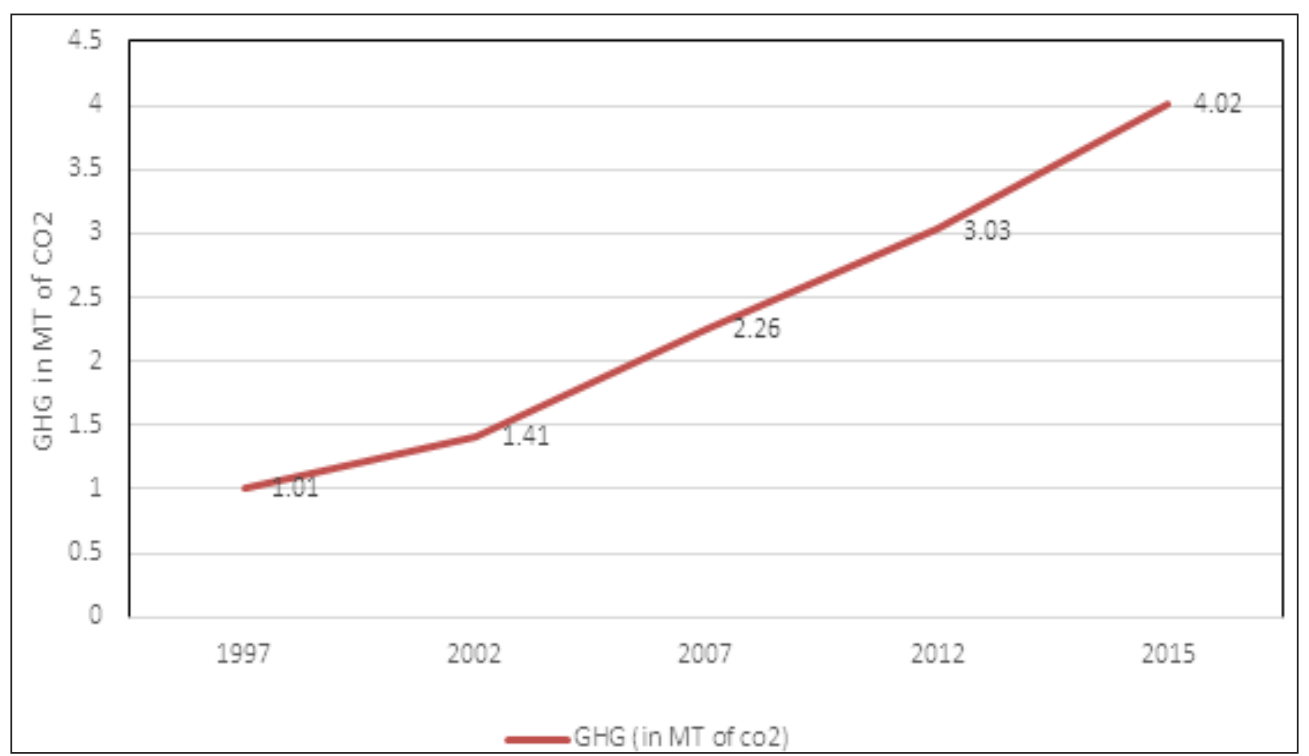

Source: KSPCB and TERI (2016-17).

Figure 9. GHG emission by the city.

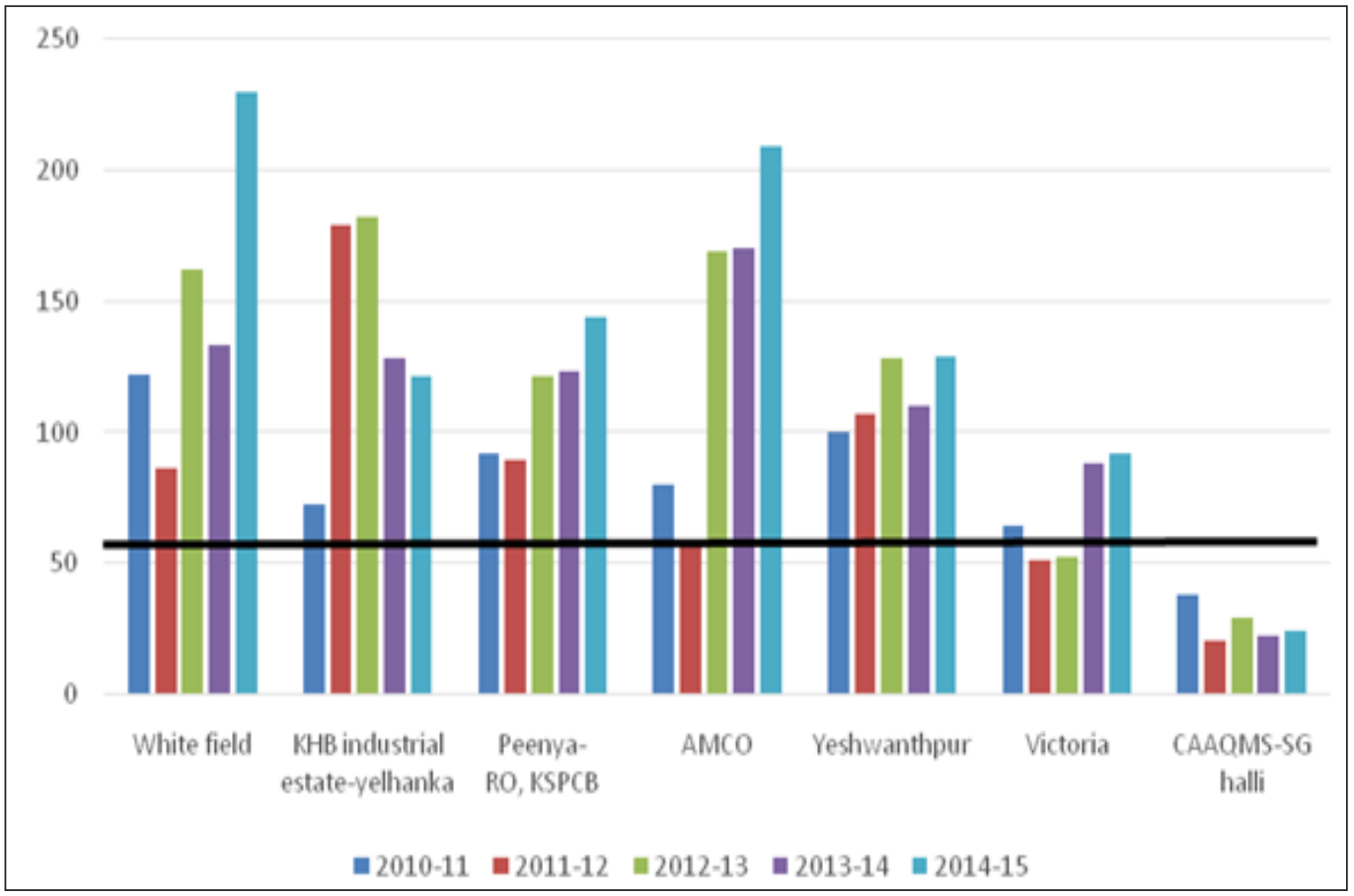

Source: KSPCB, 2016.

Figure 10. RSPM level in Bengaluru.

Figure 10, it is evident that, the RSPM levels in many monitoring stations are increasing year after year. SG halli's PM levels are below standard level, which is considered to be a referring point for the city at large hence its PM levels are lower than the standard.

\subsubsection{Air Quality Index and Bengaluru}

The Air quality index is calculated by averaging the impact of air pollutant monitored in the areas. It is an index for reporting daily air quality. It tells how clean our air is. The index has a yardstick of $0-500$ 


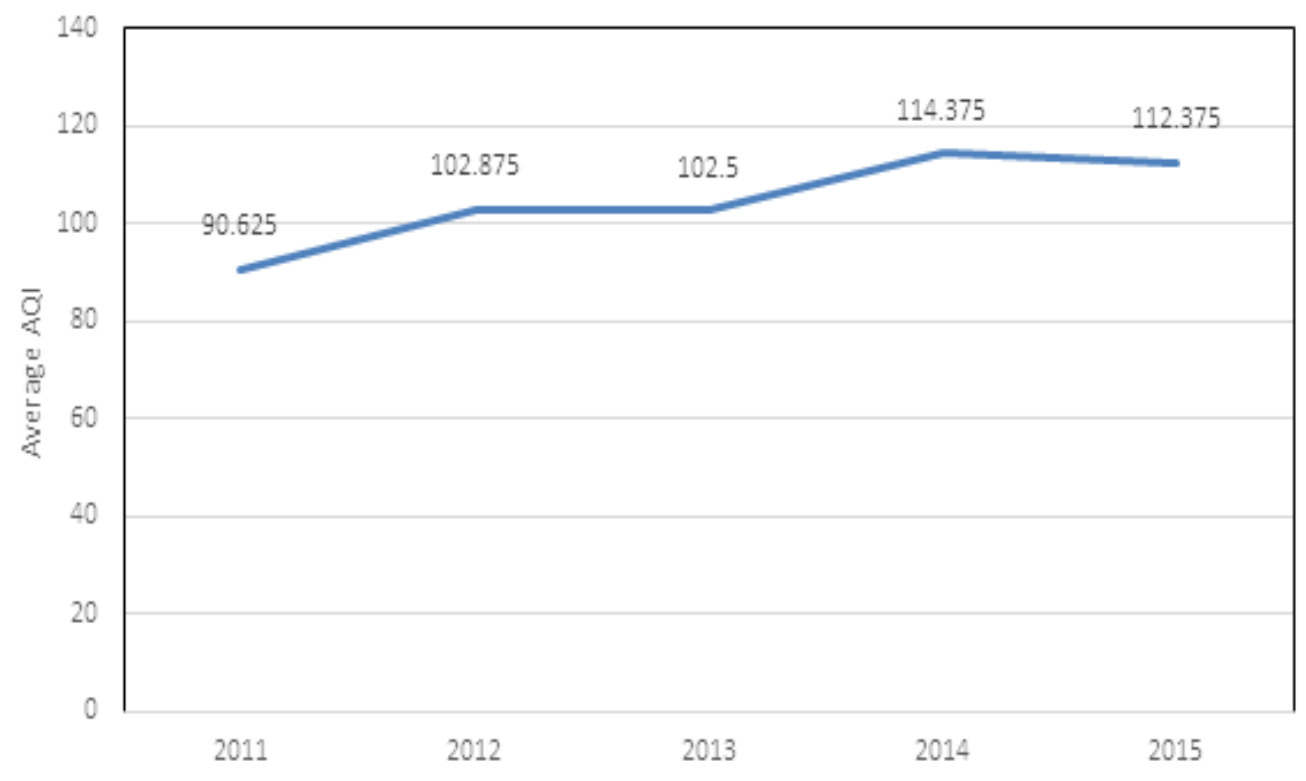

Source: KSPCB, 2015-16.

Figure 11. Average AQI in Bengaluru.

(description of yardstick is given in Appendix 2). TERI (2010) has analysed the air quality of Bengaluru and estimated the pollutants in the city which is given in the (Figure 11).

When we look at the AQI levels of Bengaluru, the level of air quality index is growing over the years. The index which was below 100 in the year 2011 has crossed the level by the end of 2015 by marking at 112 , which indicate diminishing levels in the ambient air quality of the city. This level will have negative impact on the breathing issue of sensitive people. If the emission or pollution in the city is not controlled, then the air quality will reach the index of 200 making the city's air worst to breathe.

The novelty of the paper lies in bringing a new dimension of sustainability in transport sector that is institutional sustainability.

\subsection{Institutional Sustainability}

In many of the literature, the institutional sustainability (governance issues) is either neglected or given lesser importance. But in any urban system, governance forms an important pillar for smooth working of the economy.
Governance issues in transport can be understood by indicators like condition of roads, maintenance of signals at the junction, traffic complainace. These issues are sometimes considered as a part of either economic or social sustainability, but these indicators needs a separate analysis since they deal with microlevel issues.

Road width: Many of the major roads in Bengaluru are operating at less than the standard road width (30 mts) as reported by BBMP (2011) (Table 10).

Table 10. Comparison of road width of Bengaluru's major roads

\begin{tabular}{|l|c|c|}
\hline \multicolumn{1}{|c|}{ Name of Road } & Standard Width (in mts) & Existing Width (in mts) \\
\hline Nrupatunga Road & 30 & 13 \\
\hline Sankey Road & 30 & 22 \\
\hline Airport Road & 30 & 25 \\
\hline Magadi Road & 30 & 18 \\
\hline
\end{tabular}

Source: BBMP, 2011.

According to the India Mobility Final report by Global Mobility Monitor Network 2008, the road density in Bengaluru is only $8.2 \mathrm{~km}$ per sq $\mathrm{km}$, almost one-third of the national capital (21.6 km per sq $\mathrm{km})$. 
Road capacity \& Vehicles: The limited road capacities in major roads are main cause of immobility of the area. One of the tools which measure the relation between road capacity and vehicles is vehicle to capacity ratio (V/C ratio). For smoother travel, this ratio should be less than one, but in some of the major roads of Bengaluru like Nrupatunga road, KG road, MG road, Chord road, Richmond road, Puttanna Chetty road, Sankey road are operating above $\mathrm{V} / \mathrm{C}$ ratio 1 during peak hours (BTP, 2015). This indicates the unsustainability in governance.

Bad reaches: It is estimated by BBMP that in 2015 there are around 67,000 sq mts of bad reaches, 29,210 sq mts potholes, are in Bengaluru causing not only traffic congestion, but deaths in the city.

Traffic violation: The tendency of non-compliance of traffic rules is evidently seen in overcrowded cities. Bengaluru is not an exception to this. The traffic violation mainly includes over speeding and number of traffic jumps in the city. From the available data, the over speeding in the city has increased over 9 times from 2006-2010 and number of cases booked under traffic jumps has doubled over the same period (BTP, 2015). This indicates the unsustainability in the governance to maintain a better traffic flow in the city.

\section{Implications from Finding and Suggestions}

The paper made an effort to indicate that the city is suffering from unsustainable growth of road transport by staggering high number of private modes of transportation, which is not accommodated by the road infrastructure. In this regard, it is need of the hour for the Bengaluru urban planning policy makers to look into the transport infrastructure in its sustainability than creating more roads to accommodate more vehicles. The most sustainable mode of transportation acknowledged by most countries of the world is public transportation. Even in Bengaluru, Metro trains are under way, a faster building up of this project is needed and there is further need of reducing the metro train fares to provide affordability and accessibility.
With respect to BMTC are concerned, frequency and time reliability has been a major concern. In this regard, BMTC should aim at increasing the buses to provide higher accessibility to commuters. Further, any workable policy decision needs support from the public and this applies in transport sector too. A change in the mindset of commuters to use public transport than to rely on private transport should indulge a shift. Efforts should be taken to educate the commuters and persuade them to shift to more sustainable mode of transportation, which increase their quality of life in the long run.

\section{Summary and Conclusion}

Sustainable urban transport is widely discussed topic in the literature, but very few studies are available in case of India. This paper tried to evaluate the issues of sustainability of major metropolitan cities of India and more particularly Bengaluru. The paper differs in the approach by adopting four dimensional principles of sustainability rather than three pillars of sustainability, which is commonly used in the wide literature. By bringing institutional sustainability as its fourth dimension, the paper measured the sustainability issue of Bengaluru city. Though paper limited its scope to secondary data, it covered most of the indicators which expressed the sustainability issues. By evaluating, economic, social, environmental and institutional sustainability, the result showed that, in all respect metropolitan cities of India and more specifically, Bengaluru city is experiencing unsustainable growth of transport sector. This calls for a special attention to address Bengaluru city's transport issues. Though the city has adopted Metro rail system in 2010, it looks the travel pattern in the city still has orientation towards private transportation. Hence, there is a need for demand side management of traffic flow than the traditional supply side orientation.

\section{Limitation of the Study}

a. The paper relays mainly on the secondary data available as the collection of primary data is its future objective. 
b. In evaluating the indicators for major metropolitan cities, each dimension has only one indicator. This might overlook the importance of other indicators but this is mainly done due to lack of data for the city level.

\section{References}

Ahmed Q. I., Huapu, L. \& Shi, Y. (2008). Urban Transportation equity: A case study of Beijing and Karachi, Transport Research Policy and Practice. 42(1), 125-139. https://doi.org/10.1016/j.tra.2007.06.004

Arcadis (2018). Sustainable Cities Mobility Index 2017. Arcadis. Accessed from www.arcadis.com.

Arnott, R. \& Small, Kenneth (1994). The Economics of Traffic Congestion. American Scientist. 82(5), 446-455

BBMP (Bruhat Bengaluru Mahanagara Palike) (2011). Road indentified for widening. BBMP. Accessed from www. bbmp.gov.in.

BMR (Bengaluru Metropolitan Region) (2013). Draft report on Bengaluru Metropolitan Region Revised plan 2031, BMRDA, Groupe SCE India pvt. Ltd.

BMRCL (Bengaluru Metro Rail Corporation Ltd) (2014 and 2017). Bengaluru metro rail project Phase I and II. BMRCL.

BTP (Bengaluru Traffic Police) (2015). Traffic Violation details. BTP. Accessed from www.btp.gov.in.

Cape Town (2006). Integrated Transport Plan for the City of Cape Town: 2006 to 2011. Annexure B. City of Cape Town. http://www.capetown.gov.za/en/IDP/Documents/ Statutory $\% 20$ compliance $\% 20$ plans/M.Integrated $\% 20$ Transport\%20Plan.pdf..

Census report of Karnataka (2001 \& 2011). Government of Karnataka.

CST (Centre for Sustainable Transport) (2002). Sustainable Transport Performance Indicators (STPI) - A Synopsys Report. CST.

CSTI (Centre for Sustainable Transport India) (2007). 12 Indian cities: Transport Indicators. EMBARQ (The WRI centre for Sustainable Transport) CSTI.

Dock, F. C., Ellen Greenberg \& Mark, Yamarona (2012). Multimodal and complete streets performance measures in Pasadena, California. ITE Journal. 82(1), 33-37.

Economic Survey of Karnataka (2014-15 \& 2015-16). Department of planning. programme monitoring and statistics, Government of Karnataka.

EEA (European Environment Agency) (2010). Towards a resource-efficient transport system. TERM 2009: Indicators tracking transport and environment in the European Union. No. 2/2010. EEA Report.EEA, Copenhagen.
Forbes (2017). Forbes Global 2000. Forbes. Accessed from www.forbes.com/global2000/.

GBD 2013, Collaborators (2015). Global, Regional and National Incidence, prevalence and years lived with disability for 301 acute and chronic diseases and injuries in 188 countries, 1990-2013: A systematic analysis for the Global Burden of Disease study 2013. Accessed from. ncbi.nlm.nih.gov/pubmed.

Hale, C (2011). New approaches to strategic urban transport assessment. Australian Planner. 48(3), 173-182. https:// doi.org/10.1080/07293682.2011.592505.

Houghton (1998). Ecologically sustainable development: Indicators and decision process. ARRB Transportation Research, Report 319, Australia.

IBM (2011). Frustration rising. IBM 2011 commuter pain survey. IBM.

IEA (International Energy Agency) (2011 and 2015). World Energy outlook 2011 and 2015. Paris: IEA.

IISD (International Institute for Sustainable Development) (1999). Indicators of sustainable development-Theory, Methods and Application. IISD.

IRC (Indian Road Congress) (1990). Guidelines for capacity of urban roads in plain areas. IRC. New Delhi.

Jeon, Amekedzi and Guensler (2008). Sustainability Assessment at the transport planning level: Performance measures and Indexes, Annual report, TRB.

Keyon, S., Lyon, G. \& Rafferty, J. (2002). Transport and social exclusion: Investigating the possibility of promoting inclusion through virtual mobility. Journal of Transportation Geography. 10(3), 207-219. https://doi. org/10.1016/S0966-6923(02)00012-1.

Kiran, S. \& Ashish, Verma (2016). Review of studies on mixed traffic flow: Perspectives of developing economies. Springer. 4(7).

KOTI (2011). Toward an integrated Green transportation system in Korea. Korea Transport Institute.

KSPCB (Karnataka State Pollution Control Board) (201516). Annual Reports. Accessed from KSPCB website.

Levett, R. (1998). Sustainability indicators-integrity, quality of life and environmental protection. Journal of Royal Statistical Society. 161, Part 3, 297-302. https://doi. org/10.1111/1467-985X.00109.

Litman, Todd (2011). Well measured: Developing Indicators for Sustainable and Liveable transport planning, Victoria Transport Policy Institute.

Loo, B. P. Y. (2002). Role of stated preference methods in planning for sustainable urban transportation: State of practice and future prospects. Journal of Urban Planning and Development. 128(4), 210-224. https://doi. org/10.1061/(ASCE)0733-9488(2002)128:4(210). 
Munira, S. \& Santoso, D. S. (2017). Examining public perception over outcome indicators of sustainable urban transport in Dhaka city. Case Studies on Transport Policy, Elsevier. 5(2), 167-178. https://doi.org/10.1016/j. cstp.2017.03.011.

Nicholas, J. P., Pochet, P. \& Poimboeuf, H. (2003). Towards sustainable mobility indicators: Application to Lyons conurbation. Transportation Policy. 10(3), 197-208. https://doi.org/10.1016/S0967-070X(03)00021-0.

Numbeo (2018). Travel time index. Numbeo. Accessed from www.numbeo.com.

OECD (Organisation of Economic Co-operation and Development) (2008). OECD Key environmental indicators. OECD.

OECD (Organisation of Economic Co-operation and Development) (2016). OECD Environmental Indicators: Development, Measurement and Use. Reference paper. Environmental Performance and Information Division. OECD. Paris.

OECD (Organisation of Economic Co-operation and Development) (2002). Glossary of statistical terms. Retrieved from www.stats.oecd.org/glossary.

Ramani, T., Zietsman, J., Eisele, W., Rosa, D., Spillane, D. \& B. Bochner (2009). Developing sustainable transportation performance measures for TXDOT's strategic plan. Technical report, Texas Department of Transport, College station, TX.

Reddy, B. Sudhakara \& Nathan, H. S. K. (2008). A conceptual framework for development of sustainable development indicators. IGIDR, Mumbai.

Reddy, B. Sudhakara \& Nathan, H. S. K. (2011). Urban Transport Sustainability Indicators-Approach of Multiview Black-Box (MVBB) framework. IGIDR, Mumbai.

Reddy, B. Sudhakara \& Balachandra, P. (2010). Dynamics of Urban Mobility: A Comparative analysis of Mega cities of India. IGIDR, Mumbai.

RTO (Regional transport office) (2018). Annual report of the transport department of Karnataka compiled from RTOs. Accessed from www.rto.kar.nic.in.

Shaheen, S. (2016). Moving toward a sustainable California: Exploring livability, accessibility and prosperity. UC
Berkeley Transportation sustainability research centre, California Department of Transport.

Sa'nchez, T. W., Stolz, R. \& Ma. J. S. (2003). Moving to Equity: Addressing Inequitable effects of transportation policies on Minorities. The civil rights project at Harvard University. Cambridge, MA.

TERI (2016-17). Energy Data Yearbook and Directory 2016-17. New Delhi.

TERI Report (2010). Air quality assessment, emission inventory \& source apportionment study of Bengaluru City.

UN (United Nations) (2017). World Cities 2016. Economic and Social Affairs, UN.

UNCSD (United Nation Commission for Sustainable Development) (1996). Indicators of sustainable development framework and methodologies. Background paper 3, Division for Sustainable Development, United Nation, New York.

US Bureau of Labour Statistics (2010). Travel: BLS Spotlight on Travel. USA.

USEPA (United States Environmental Protection Agency) (2008). Sustainable development: Concept and methods, USEPA, USA.

WBCSD (2004). Mobility 2030: Meeting the challenges to sustainability. WBCSD.

World Bank (1996). Sustainable Transport: Priorities for Policy Reform. The International Bank for Reconstruction and Development, the World Bank. Washington D C.

World Bank (2016). The cost of Air pollution: Strengthening the Economic case for Action. Washington DC.

World Bank Report (2013). Diagnostic Assessment of select environmental challenges in India: An assessment of physical and monetary losses of environmental health and natural resources. I. World Bank.

World Urbanization Report (2015). Cities for All. World Bank. Washington D C.

Zietsman, J. \& Rilett, L. R. (2001). Sustainable transportation: fad or fabulous. Paper presented to the $20^{\text {th }}$ Annual South African Transport Conference, South Africa, 16-20 July. 


\section{Appendix 1}

Criteria for good sustainable indicator

\begin{tabular}{|l|l|}
\hline Criteria & \multicolumn{1}{|c|}{ Description } \\
\hline Acceptable & Indicator must have general acceptability by the policy makers and public. \\
\hline Accurate & Must be based on accurate information and data. \\
\hline Affordable & Must be able to adopt data which is readily available or at less cost. \\
\hline Appropriate level of details & Must be able to furnish the required details without manipulating the information. \\
\hline Benchmark oriented & Must have a benchmark to which the indicator values can be compared. \\
\hline Quantifiable & Should be based on quantifiable data. \\
\hline Relevant & Must be compatible for the objective under study. \\
\hline Sensitive & Must provide the information if there is any changes in the parameters. \\
\hline Comprehendible & Must be easily understandable to the policy maker and public at large. \\
\hline
\end{tabular}

Source: Ramani, et al, (2009) and UNCSD (1996).

\section{Appendix 2}

Yardstick definition of AQI

\begin{tabular}{|l|l|}
\hline Index & Description \\
\hline $0-50$ & Good-minimal impact on health \\
\hline $51-100$ & Satisfactory-Minor breathing problems \\
\hline $101-200$ & Moderate-Breathing discomfort to sensitive people \\
\hline $201-300$ & Poor-Breathing discomfort \\
\hline $301-400$ & Very Poor-Respiratory diseases \\
\hline$>400$ & Worst-Respiratory effect on healthy people \\
\hline
\end{tabular}

Source: KSPCB. 